\title{
DOUTRINA
}

\section{Decretação e Isenções do Aqueduto Legal}

JAIR TOVAR

\section{FORMAS DE DECRETAÇÃO DO ÔNUS}

$\mathrm{O}$

Código de Águas estipula que a servidão legal de aqueduto seja decretada pelo Govêrno, no caso de aproveitamento das águas em virtude de concessão por utilidade pública; (1) e pelo juiz, nos outros casos.

Cogita-se aí, exclusivamente, do caso de decretação do ônus, o que não impede poder a sua instituição operar-se por outras formas, que prescindem da coação da lei, passando, em tais casos, o aqueduto, a se incluir entre as servidões convencionais, como acontece em relação àqueles resultantes de contratos, de testamentos, de prescrição e de partilhas. (2)

Trataremos de outra feita dessas modalidades de constituição do aqueduto enquanto nos cingiremos agora a hipótest da decretação aludida no Código.

Essa decretação pode ser feita pelo chefe do Poder Executivo Federal, Estadual ou Municipal (3) e podemos denominá-la, quando assim o é, decretação governamental ou administrativa, em confronto com aquela do Poder Judiciário (juiz ou tribunal), a que se deve chamar, por isso mesmo, decretação judicial.

\section{DECRETAÇÃO GOVERNAMENTAL}

A decretação governamental só tem cabimento no caso de aproveitamento das águas em virtude de concessão, enquanto que a decretação judicial pode ser solicitada para todos os outros casos, em que se integrem as exigências para a obtenção do aqueduto, por fôrça da lei.

A decretação governamental ou administrativa pode ser federal, estadual ou municipal, conforme o respectivo domínio sôbre as águas a que a concessảo se referir, ou conforme os serviços públicos a que se destine a derivação, de acôrdo com os dispositivos do Código e as leis especiais sôbre os mesmos serviços.

(1) Art. 120: "A servidã́o que está em causa será decretada pelo Govêrno, no caso de aproveitamento das águas em virtude de concessão por utilidade pública e pelo juiz nos outros casos."

(2) Carvalho de MendonçA, Rios e Åguas correntes, n. ${ }^{\circ} 186$.

(3) Artigo 62 do Código de Águas. 
São excluídas dessa regra de caráter geral as concessões ou autorizações para derivações destinadas à produção de energia elétrica, as quais são feitas exclusivamente pela União, salvo no caso de transferência de suas atribuiçčes aos Estados, dentro do estabelecido em preceitos especiais que estão capitulados nos arts. 191 a 194 do Código de Águas. (4)

Ainda se requer, no inciso legal do art. 120 que, para a decretação governamental, a concessão se tenha feito por utilidade pública, cuja noção já tivemos oportunidade de ressaltar. (5)

Isso importa em dizer que não se limita a faculdade do poder governamental às águas públicas, mas estende-se também às águas particulares, e dela pode utilizar-se sempre que sôbre a utilidade pública seja fundamentado o ato da decretação.

Dêsse modo, embora muitas vêzes esteja a hipótese fora da alçada governamental, por ser a atribuição conferida ao poder judiciário, desde que intercorra a utilidade pública como exigente da concessão, ao Govêrno reconhece a lei o direito de realizar, outrossim, a decretação da servidão.

\section{DECRETAÇÃO JUDICIAL}

A decretação judicial é aquela obtida por meio de decisão juđiciária, seja ela proferida por juiz singular, tendo a sentença passado em julgado, seja ela resolvida por acórdão irrecorrível de Tribunal.

Pelo art. 568, do Código Civil, tôdas as questões relativas a servidões de águas e às indenizações correspondentes deviam ser pleiteadas por meio de ação sumária. (6)

Esta era uma tradição do nosso direito, provinda do direito português, (7) onde se determinava que tôdas as ações concernentes às águas e indenizações respectivas - fôssem possessórias ou petitórias - gozassem do favor inerente a processamento mais rápido, para que assim também mais prontamente fôsse atendida a correlata relação jurídica, por sua natureza em geral merecedora dêsse favor.

Ao tempo em que cada ação tinha um nome adequado, entre as petitórias surgia, com credencial de apropriada para o fim de decretação judicial, a chamada ação confessória.

LOBÃo assim aceitava a sua definição: - "Ação confessória é uma ação real, em virtude da qual pretende-se um direito de servidão, que nos é devido. ou ao nosso prédio, sôbre o prédio de outro".

(4) Idem e artigo 63 do mesmo Código.

(5) "Revista do Serviço Público", vol. 66 n. ${ }^{\circ}$ 3, págs. 527 a 535.

(6) Causas ou ações sumárias eram aquelas que, observando a ordem natural do processo, prescindiam de certas formalidades e ficavam subordinadas a prazos mais restritos, sendo as respectivas sentenças suscetíveis de apelação no efeito só devolutivo. Veja-se Pereira E SOUZA, Prims. Linhas, s̊ 472,474 e 476.

(7) SÁ PEreira, man. do Cod. Civ., vol. VIII, n..$^{\circ} 99$. 
E o lembrado reinícola observa: - "Esta ação compete ao proprietário do prédio, para o qual contende ser devida a servidão que se the nega ou perturba". (8)

Para as violações de caráter possessório, eram aplicados os respectivos remédios de manutenção ou de restituição, sempre com o caráter sumário, os quais iam encontrar suas fontes no direito romano, nos vários interditos de nomenclatura diversa para cada caso, avultando, entre êles, como o mais comum para a proteção do aqueduto, o de aqua quotidiana et aestiva.

Por ser a ação sumária um favor reconhecido a quem demandasse sôbre águas, o direito não o inibia da utilização da ação ordinária, quando fôsse o seu processo preferível, de vez que, assim, também se dilatavam ao réu os meios e prazos de defesa.

Tôda a complicada nomenclatura das ações de outrora encontra-se hoje simplificada pela sistemática processual moderna, em cujo ritmo entrou o sistema brasileiro.

Pela via comum do processo ordinário é que deve ser pedida a decretação da servidão de aqueduto, no caso de ocorrência de qualquer das hipóteses previstas nos artigos 117 do Código de Águas e 567 do Código Civil, desde que não se trate de concessão por utilidade pública.

\section{DECRETAÇÃO NAS AÇÕES DE PARTILHA}

O vigente Código processual da República diz, no art. 291, que o proceșso ordinário regulará as ações para as quais não prescreve rito especial.

Mas, além dessa via comum ainda é possível a decretação judicial do aqueduto, por efeito dos processos especiais de divisão e de inventário.

$\mathrm{O}$ art. 446 do Código Processual, no $\S 2^{\circ}$, ao se referir à partilha resultante da ação de divisão, assim preceitúa: "na mesma fôlha de pagamento serão declaradas as servidões que recaírem sôbre o quinhão demarcado ou a seu favor forem instituídas, designando-se o lugar, modo e condições do seu exercício".

De igual forma o art. 506 do mesmo Código, em harmonia com o disposto no art. 505, n. ${ }^{\circ}$ II, dispõe: "na folha de pagamento de cada herdeiro serão declaradas, com a possível exatidão, as confrontações dos bens e as servidões a que ficarem sujeitos, evitando-se dividir as terras por quota-partes ideais".

\section{QUEM PODE PEDIR A SERVIDÃO DE AQUEDUTO}

O Código de Águas não tem nenhum dispositivo explícito nesse sentido, mas o Código Civil começa o art. 567, referente ao aqueduto, da seguinte forma: "é permitido a quem quer que seja canalizar, etc.".

Tem-se, por isso, reconhecido que êsse direito compete a quem tenha, temporária ou permanentemente, direito de se servir das águas, seja pessoa

(8- LOBÃo, Diss., § 234. 
física ou seja pessoa jurídica, seja em decorrência de um direito real, seja em conseqüência de um direito pessoal de uso e gôzo do titular do fundo para onde as mesmas devem ser conduzidas.

Assim, tem-se reconhecido ainda que tanto o possuidor de boa como o de má fé podem invocar o direito ao aqueduto, pois que as primeiras necessidades da vida tanto as tem um como outro, e cada qual tem o direito de satisfazê-las. (9)

Não só o proprietário, como o enfiteuta, o usufrutuário, o usuário, o habitante, o anticresista, o inquilino, o arrendatário, o concessionário, todos estão habilitados para o exercício da prerrogativa legal, desde que se verifique qualquer das hipóteses previstas no art. 117 do Código de Águas, sem prejuízo de direitos já assegurados a terceiros.

Ainda cumpre assinalar que o aqueduto pode ser pedido para qualquer espécie de águas, procedam de onde procederem, provenham elas de ação exclusiva da própria natureza ou do concurso dos homens, derivem de fontes, chuvas, correntes navegáveis ou não, lagos ou charcos.

Do exposto, que resulta da própria letra do dispositivo legal, importa em reconhecer-se que tomou compreensão mais dilatada êsse direito de pedir o aqueduto, assegurado primitivamente pelo nosso direito só em favor de quem tivesse o domínio pleno ou útil do prédio a ser beneficiado, conquanto já se o permitisse ao possuidor habilitado à prescrição aquisitiva e para quem tivesse o domínio resolúvel. (10)

\section{A DIREÇÃO, NATUREZA E FORMA DO AQUEDUTO DEVEM ATENDER AO MENOR PREJUIZO POSSIVEL PARA O SERVIENTE}

$\mathrm{O}$ aqueduto está subordinado, como tôda servidão, ao tradicional preceito relativo a elas, de que os atos de paciência do serviente devam ser tanto menos gravosos quanto até onde possa o domínante fazer o uso regular e legítimo do seu direito real.

Foi de uma consideração conjugada do que dispõem os arts 702,703 e 704 do Código Civil, especialmente dos dois últimos, que nasceu do legislador do Cóđigo de Águas o art. 123. (11)

$\mathrm{O}$ art. 702 determina que o dono do prédio serviente não poderá embaraçar de modo algum o uso legítimo da servidão.

Para compensar-lhe esta passividade, o codificador civil estabeleceu os dois outros dispositivos, o primeiro dos quais assegura ao dono do prédio serviente o direito de remover a servidão de um local para outro, contanto que o faça à sua custa, e não diminua, em nada, as vantagens do prédio dominante.

(9) Pacifici-Mazzoni, Ist. cii Dir. Civ. Ital., vol. III, pág. II, n. ${ }^{\circ} 252$.

(10) Carvalho de Mendonça, op cit., n. ${ }^{\circ} 175$; Lobão, Dissert. $\$ 17$; Lafayetre, Dir. das Coisas, § 122-B, nota 4. - Segundo êsses, nem ao locatário, nem ao comodatário nem ao arrenđatárí, e à todos quantos estivessem em condições idênticas, possuindo em nome alheio, era permissível o direito de pedir o aqueduto

(11) Artigo 123 do C. A.: "A direção, natureza e forma do aqueduto devem atender ao menor prejuízo para prédio serviente." 
O segundo faz restringir o uso da servidão às necessidades do prédio dominante, evitando, quanto possível, agravar o encargo do prédio serviente.

Numa correspondência mais direta com o primeiro dispositivo existe, ainda, no Código de Águas o art. 131, onde se reafirma ao dono do prédio serviente o direito de remover a servidão dentro do espírito constante do art. 703 da Lei civil. (12)

A diferença que separa os dois textos reside em que um se refere à servidão, que se procura instituir, enquanto o outro regula a faculdade, que é reconhecida no caso de servidão já constituída.

As fontes romanas recomendavam que a servidão deve ser exercida civiliter, (13) isto é, de forma que ao titular do prédio dominante não seja concedido extendê-la ou ampliá-la a seu arbítrio, com prejuízo do serviente.

A lei, reconhecendo a existência da limitação da propriedade, procura fazer com que o paciente sofra tanto menos quanto não venha prejudicar a utilidade reconhecida em favor do prédio dominante. (14)

$\mathrm{E}$ daí, tendo em conta as suas necessidades, de acôrdo com os intúitos da servidão, preconiza para seu estabelecimento, a que pode ser constrangido o serviente, que se deva atender na direção, na natureza e na forma do aqueduto, ao que fôr menos prejudicial.

Naturalmente essa recomendação tem que ser encarada sob o critério da relatividade.

Compreende-se bem que a direção menos prejudicial ao serviente, que tenha um campo cultivado pelo caminho mais curto, seria evitar-se que êsse campo fôsse atravessado pelo aqueduto.

Mas isso constituiria muitas vêzes anulação do direito do aqueduto.

Resulta daí, para a boa aplicação do intúito legal, que o prudente arbítrio do julgador delibere tendo à vista o preceito legal sem esquecer o direito em função do qual êle existe.

O que assim acontece em relação à direção, também é de ser dito em relação à natureza e a forma.

\section{AÇÕES RELATIVAS AO PRÉDIO SERVIENTE}

A decretação da servidão, ou seja pelo ato administrativo ou seja pela sentença judicial, importa no fundo nas conseqüências de um processo de desapropriação, visto que em geral priva o prédio serviente de determinada área e lhe impõe certos encargos, que não era obrigado a suportar, se não existisse a servidão.

(12) Artigo 703 do C. Civil: "Pode o dono do prédio serviente remover, de um local para outro, a servidão, contanto que o faça à sua custı, e não diminua, em nada, as vantagens do prédio dominante."

(13) Clovis, Cod. Civ, comentado, vol. III, obs. ao art. 704.

(14) Art. 704 do Cód. Civ. "Restringir-se-á o uso da servidão às necessidades do prédio dominante, evitando, tanto quanto possivel, agravar o encargo do prédio serviente: Parágrafo único: Constituída para certo fim, a servidão não se pode ampliar a outro." 
Daí porque os parágrafos do art. 120 do Código de Águas cogitam do assunto da indenização devida ao prédio serviente, como compensação dos prejuízos e depreciações sofridas.

Antes, porém, em têrmos peremptórios assinala que, nos casos do aqueduto legal, nenhuma ação contra o proprietário serviente e nenhum encargo sôbre o mesmo prédio poderá obstar que a servidão se constitua.

Quando a lei tomou sob sua tutela a constituição dos aquedutos, desde que verificadas as hipóteses constantes da enumeração do art. 117 do Código de Águas, é porque o exigia um interêsse social e, por assim - público, na construção dos mesmos.

Não poderia, portanto, a satisfação dos seus intúitos, ficar subordinada a querelas porventura existentes entre os que se julguem com quaisquer direitos sôbre o prédio serviente.

As ações podem surgir entre êles, subsistir e resolver-se; mas nenhuma delas poderá obstar a execução do aqueduto decretado.

Não seria, entretanto, racional que se impedisse a reivindicação de direitos ou defesa dos mesmos contra estranhos, por parte do verdadeiro titular do prédio.

Por êsse motivo reservou-lhes a lei a faculdade de disputarem os seus direitos sôbre o preço da indenização resultante da constituição do aqueduto.

Assim, uma vez surjam dúvidas relativas ao prédio serviente, em virtude de ações ajuizadas, o preço dessa indenização será depositado, na forma do art. 318 do Código Processual, para que sôbre êle disputem os interessados a prevalência dos seus interêsses. (15)

Nunca, porém, assistirá a tais interessados o direito à propositura de uma ação que impeça o curso normal do processo de constituição do aqueduto.

De tal arte, as intervenções por oposição, os embargos de terceiros e outras hipóteses processuais semelhantes, não terão cabimento para obstar o favor legal do aqueduto coato.

Tal não acontece no caso de aqueduto convencional, onde as ações podem surgir em tôdas as suas modalidades aplicáveis, desde que haja um direito a defender, prevalente contra a convenção estipulada.

Não há aí de permeio a satisfação de um interêsse social na execução do aqueduto; e nesse caso tomam corpo tôdas as circunstâncias que seriam neutralizadas pela concorrência dêsse interêsse.

\section{INDENIZAÇÃO}

$\mathrm{O} \S 2 .^{\circ}$ do art. $120 \mathrm{diz}$ que, não havendo acôrdo entre os interessados sôbre o preço da indenização, será êle fixado pelo juiz, ouvidos os peritos, que êles nomearem.

(15) Art. 318 do Cód. do Processo Civ.: "Se a ação tiver sido intentada por haver ignorância ou dúvida sôbre quem deva receber, efetuar-se-á o depósito no dia prefixado para o recebimento, etc.". 
Como se vê, a hipótese do não acôrdo entre os interessados comporta sempre a instauração de um processo judicial, seja a decretação do aqueduto por fôrça de ato administrativo, seja por deliberação judicial.

Se a decretação decorre de ação judicial, na respectiva execução se fará o arbitramento dessa indenização, com a louvação de peritos, que em tudo procederão como nos demais arbitramentos judiciais, mas atendendo a que essa indenização não compreenda o valor do terreno, porém constitua ùnicamente o uso do terreno ocupado pelo aqueduto e de um espaço de cada um dos lados em tôda sua extensão.

Se a decretação fôr administrativa, a indenização tem que ser arbitrada também judicialmente, em processo especial, observando-se assim a determinação legal, que manda seja a indenização fixada pelo juiz.

Essa fixação se fará entre os dois valores em contenção: o pedido e o . da oferta de pagamento, tendo-se à vista o laudo dos peritos.

Se os peritos forem divergentes, é indubitável que pela sistemática processual vigente, (16) o juiz deverá nomear um terceiro, a fim de opinar sôbre os laudos divergentes.

Tendo à vista o pronunciamento dos peritos, o juiz não fica, entretanto, adstrito ao laudo ou laudos proferidos, e pode decidir atendendo a circunstâncias relevantes, que não tenham sido convenientemente consideradas. (17)

\section{LIMITE DE INDENIZAÇÃO}

Dizendo que a indenização não compreende o valor do terreno, quis a lei pôr em relêvo o fato de se não tratar aqui pròpriamente de uma desapropriação de domínio, pois que o titular do prédio serviente continua com êle.

Essa a razão porque, logo a seguir esclarece que essa indenização deva corresponder tão sòmente ao justo preço do uso do terreno ocupado e da faixa adjacente prevista para cada lado do aqueduto em tôda sua extensão.

Pelo art. 674, n. ${ }^{\circ}$ II, do Código Civil, o uso constitui um direito real sôbre a coisa alheia.

Em conseqüência do seu estabelecimentc; reconhece a lei civil ao usuário o direito à fruição da utilidade da coisa, no quanto exigirem as necessidades pessoais suas e de sua família, compreendendo-se nesta o seu cônjuge, filhos solteiros ainda que ilegítimos e pessoas do seu serviço doméstico, avaliadas as necessidades pessoais segundo a condição de cada um. (18)

É preciso aqui ao intérprete da lei uma acomodação de conceitos, para que não se entrechoquem, quando da aplicação de cada um.

亡 evidente que a servidão legal de aqueduto sòmente pode ser considerada uma servidão real, isto é, de prédio em favor de outro prédio; enquanto

(16) Dec.-lei n. ${ }^{\circ} 8.570$, de 8-1-1946, art. 129.

(17) Neves E Castro, Teor. clas Provas, ed. Pontes de Miranda, 1917, n. 112.

(18) C. Civil, arts. 742 a 745. 
a servidão convencional de aqueduto pode assumir o aspecto de pessoal, ou seja, estabelecida em favor de determinada pessoa ou pessoas.

O uso é outro direito real, com característica fundamental diversa, pois que é estabelecido como ônus sôbre um prédio, não em favor de outro prédio, mas de uma pessoa.

Como pois conjugar a letra da lei com a substância dessas instituições?

Conferindo-se êsse direito de uso sòmente àquele que fôr titular do prédio em favor do qual foi decretado o aqueduto com os direitos e extensão previstos na lei civil para aquêle direito real, em harmonia com as restrições opostas pela mesma lei em favor do serviente e atendendo-se à hipótese determinante de sua concessão.

O espaço de uso em cada lado, da largura que fôr necessária, em tôda extensão do aqueduto, é o destinado à utilização do dominante nos serviços inerentes à sua conservação, construção e limpeza, aos quais se refere o art. 126 do Código de Águas, e por via do qual se realiza o direito de trânsito, sempre implícito na compreensão tradicional da servidão de aqueduto e ao qual faz menção, de modo expresso, o art. 127 do Código de Águas.

Como tais serviços e o trânsito constituem atos comuns e necessários à instituição do aqueduto, o legislador desde logo os preveniu.

\section{PRESTAÇÃO DE CAUÇÃO}

O Código de Águas deixou implìcitamente assentada regra em contrário à não indenização dos danos, e vai mais longe deferindo até, ao titular do prédio serviente, o direito de exigir do dominante a prestação de uma caução pelos prejuízos que possa ocasionar.

E nos têrmos em que a obrigação está definida, não é possível aceitar a divergência, atendendo-se à origem e à natureza dos danos, tal como vimos estudada na doutrina, também nesta peculiaridade.

A lei para dar ao serviente maior segurança de uma indenização em frente de possíveis danos assegura-lhe até o direito de exigir, do senhor ou possuidor do prédio dominınte, a prestação de uma caução pelos prejuízos que possa ocasionar.

Essa caução, a que se refere o artigo, é aquela mesma prevista no artigo 529 do Código Civil: "O proprietário, ou o inquilino, de um prédio em que alguém tem direito de fazer obras, pode, no caso de dano iminente, exigir do autor delas as precisas seguranças contra o prejuízo eventual".

A expressão "dano iminente" corresponde àquela que os velhos praxistas denominavam "dano infector", (19) e que se costuma também denominar

CORRÊA TElles preconizava, na sua Doutrina das Ações, (20) a prestação dessa caução, "em todos os casos de ter o Autor justo receio de algum "dano futuro" ou por vício de obras, ou por fatos do vizinho".

(19) JoÃo LUIz ALVES, op., cit., comentários ao art. 529 e 555.

(20) Doutrina das ações, ed. Teixeira de Freitas, § 97. 
Como tôdas as ações que estão no cíclo das águas, prøcessava-se sumàriamente em obediência ao preceito do art. 568 do Código Civil, conquanto CÂNDIDO DE OliveIRA FILHo, (21) fundamentado em MourA, (22) recomendasse a ação ordinária, conforme o valor da causa.

Hoje, em face do vigente Código Processual Brasileiro, tôdas as prestaçṍes de caução estão reguladas no livro referente aos processos acessórios,

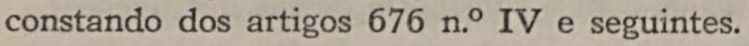

\section{ISENÇÕES AO AQUEDUTO LEGAL}

As casas de habitação e os pátios, jardins, alamedas ou quintais contíguos às casas são, em princípio, excluídas do gravame da servidão legal, mesmo que se concretize qualquer das hipóteses das letras a e $d$ do art. 117 do Código de Águas.

E o que preceitua o art. 118 seguinte.

Já isso acontecia no nosso direito anterior, que excluía da paciência compulsória da servidão "os quintais, hortas, jardins, pomares e cêrcas de casas rústicas ou urbanas", (23) numa enumeração evidentemente mais ampla do que a contida no citado Código.

O alvará de 27 de novembro de 1804 , de tão constante invocação, falava, no seu $\S 12$, "nas quintas nobres e muradas e os quintais dos prédios urbanos nas cidades ou vilas".

CARvalho DE Mendonça explica que a expressão "casas" abrange tôdas as construções ou edifícios e não, exclusivamente, as habitações e seus quintais, hortas, pomares, jardins - mas todos os terrenos, mesmo os abertos, anexos às habitações. (24)

Essa compreensão dilatada provém do direito europeu.

O Código Civil italiano refere-se à exceção relativa às "casas, pátios, jardins e áreas aos mesmos atinentes", (25) e entende-se, por identidade de razões, compreendidos na disposição legal, os museus, as galerias, as pinacotecas, as bibliotecas, os magazins, as lojas, as oficinas e estabelecimentos semeIhantes. (26)

O Código Civil brasileiro no seu art. 567, que teve como fonte o art. 456 do Código Civil português, segundo confessou o codificador pátrio, (27) também já preconizava a exceção e nela incluía as "chácaras ou sítios murados, quintais, pátios, hortas ou jardins".

(21) Prática Civil, vol. 4 , obs. 1 ao n. 395.

(22) Mantral do Edificante, \& 296.

(23) LAFAYETTE, Direito das coisas, $\$ 122$, n. $^{\circ} 5$.

(24) Op. cit., n. ${ }^{\circ} 175$.

(25) Art. 598: "le case, $i$ cortili, $i$ biardini e le aie ad esse attinenti".

(26) Marchi, in Diz. Scialoja, \$ $3 .^{\circ}$; PACIFICI-MazzonI, vol. III, parte segunda, ก. ${ }^{\circ} 253$. rada".

(27) Clovis Bevilaqua, Cod. Civ. com., vol. III, art. 567, em Legislação compa- 
Essa redação da lei com a expressão - "murados" - tem dado lugar a interpretações que, ao invés de clarearem sua inteligência, a tornam confusa.

Eis a razão por que um dos nossos civilistas assim a criticou:

- "O Código, na verdade, não foi feliz em falar em chácaras ou sítios murados, mas deixa perceber, apesar de tudo, que ao se referir ao muro, queria exprimir que ficava isento do ônus do aqueduto tudo que formasse com a casa um só todo, o que melhor traduziu com a idéia do muro, servindo de limites a êste todo beneficiado pelo favor da lei". (28)

Realmente, como bem se tem observado em conclusão, o fato de não estar cercada certa parte do conjunto integrante de uma habitação, seja seu pomar ou seu jardim, năo justifica a exclusão do benefício legal, tanto assim que o Código de Águas expungiu do seu art. 118 a expressão criticada.

E toi mais longe, não distinguindo a isenção, quer se trate de prédio rústico, quer se trate de prédio urbano.

Servindo-se da lição de SÁ PEREIRA, que já ressalvava anteriormente as dependências dos prédios urbanos, estejam ou não muradas, foi mais além e declarou o favor para essas dependências, sejam elas rústicas ou urbanas, estejam ou não muradas. (29)

Aliás, assim já o entendia o direito italiano. (30)

\section{AS ISENÇÕES NO DIREITO ESTRANGEIRO}

Em regra, estão previstas no direito de outras nações, de que nos socorremos subsidiàriamente, as mesmas isenções constantes do Código Civil e Código de Åguas.

O Código Italiano, a cujo texto fizemos referência, foi neste particular derrogado por uma lei especial, votada para permitir o saneamento da cidade de Nápolis, sendo, por fôrça de considerações higiênicas, concedida a passagem coacta também nesses lugares isentados pelo direito comum de servidão de aqueduto. (31)

Cogitou-se da limitação do âmbito das isenções da lei, por ocasião de se discutir o projeto PISANELl, não obstante sua conformidade neste ponto com o Código Albertino, (32) ressalvando-se, de modo exclusivo, as casas e sòmente depois de apreciadas e pesadas as circunstâncias especiais a cada caso - os pátios, os jardins e os eirados a ela atinentes.

(28) Carvalho dos Santos, Cod. Civ. interpretado. vol. VIII, obs. 9 ao art. 567.

(29) "Uma chácara ou sítio, murados ou não murados, podem ser indistintamente rústicos ou urbanos. Se o muro fôsse a característica especificadora, dever-se-ia sujeitar à servidão uma chácara não murada, embora urbana, como dever-se-ia dela isentar uma chácara murada, embora rústica. Mas salta aos olhos que isto contraria tôda a razão inspiradora do texto legal". - Man. do Cod. Civ., vol. VIII, n. ${ }^{\circ}$ 96. Ist. di Dir. Civ. Italiano,

vol. III, partè II, in fine.

(30) PACIFICI-MAZZONI.

(31) Lomonaco, Ist. di Dir. Civ. Ltaliano, vol. III, pág. 393. 
Entre as razões fortes com que procuraram justificar a exclusiva isenção das casas, estava como principal a de que elas em geral ocupam pequenas áreas; mas essa razão acabou afinal prevalecendo também para as suas dependências. (33)

Daí projetou-se até nós como solução que melhor concilia os interêsses determinantes do aqueduto compulsório com o direito de propriedade, já tanto mutilado pelas investidas do socialismo de um lado e, de outro, pelas intolerâncias dos governos que se intitulam fortes.

O Código Civil português, de que procedeu a disposição do nosso Código Civil (art. 567), segundo confessa Clovis Bevilaqua, tinha a seguinte redação, que não foi modificada pelo art. 114 da Lei de Águas, no tocante à isenção em aprêço:

- "Não sendo quintas muradas ou quintais, jardins, hortas ou pátios adjacentes a prédios urbanos."

Por "quintas muradas", esclarece um seu comentador, entende-se, segundo o seu significado de origem castelhana, qualquer propriedade vedada tendo dentro um prédio urbano. (34)

No direịto português êsse obstáculo pode ser afastado pela expropriação, com fundamento no regime das concessões por utilidade pública, desde que por meio regular se verifique a impossibilidade material e econômica de executar as obras sem a utilização dos lugares isentos, o que igualmente está previsto entre nós, como a seguir veremos.

Segundo VELOSO DE ALMEIDA, compreende-se bem que se entre os prédios urbanos e suas dependências se interpuser qualquer caminho público, estão elas obrigadas ao ônus da servidão. (35)

A ressalva das mesmas isenções está contida na lei francesa de 1845. artigo segundo.

Um dos seus apreciadores assinalou que essas isenções não são de ordem pública, pelo que os proprietários dos prédios tutelados por elas podem consentir no estabelecimento do gravame. (36)

Têm correspondência com as isenções da nossa lei aquelas previstas; no art. 570 do Código Civil do Uruguai (as casas, os currais, pátios, hortas e jardins que delas dependam); no Código venezuelano, art. 652 (os edifícios, seus pátios, jardins, currais e demais dependências); no Código Civil Colombiano, art. 920 (as casas e os currais, pátios, hortas e jardins qu edêles dependam) e mais no art. 3.084 do Código Civil Argentino (casas, currais, os pátios e jardins, que delas dependam de superfície menor de 10.000 metros quadrados); Código Civil Chileno, art. 3.086. (37)

(32) Foscini, Teorica delle acque, pág. 87, ed. 1883.

(33) Idem, in fine.

(34) Veloso DE Almeida, Dir. des Águas, n. ${ }^{\circ} 194$.

(35) Idem, op. e loc. cits.

(36) Baudry-Lacantinerie et Cheveau, Trat. Teo. e Prat. di Dir. Civ. (ed. Vallardi), n. ${ }^{\circ} 889$.

(37) In Dionísio Gama, Das Águas, $3 .^{a}$ parte. 


\section{COMPREENSÃO DO OBJETO DAS ISENSÕES}

Inicialmente, o Código de Águas refere-se, no tocante à exclusão da paciência do aqueduto legal, às "casas de habitação".

Parece indubitável que o legislador quis com isso excluir todo e qua!quer outro edifício que não fôsse destinado a habitação.

$\mathrm{Na}$ Itália, em tôrno do assunto houve uma demorada discussão, relativamente a se saber se a expressão case, do respectivo Código, era compreensiva, exclusivamente, das habitações, conforme opinava Mazzoni, (38) ou estendia-se a todos os edifícios, quaisquer que êles fôssem e servissem aos usos da vida humana.

A interpretação então prevalente foi a de que a exceção não podia aludir sòmente às casas construídas para habitação, mas, também, àquelas que potencialmente fôssem capazes de ter a mesma destinação, conquanto não imediatamente; mas indispensáveis mediatamente às necessidades da vida humana e às exigências da sociedade. (39)

Segundo Gianzana, os motivos determinantes da isenção para aquéle caso, quais sejam os de remover tanto quanto possíveis os perigos de ruína que podem ser ocasionados às casas de habitações servientes, por efeito da corrosão produzida pela vizinhança das águas, êsses mesmos motivos devem ser estimados no tocante aos outros edifícios embora não destinados à habitação. (40)

Para BoRSARI, na expressão "casa" se entendem todos os edifícios que servem aos usos da vida humana; (41) não sòmente aquêles que são destinados à habitação, mas também os que são destinados a conter seja o que fôr, animado ou inanimado, que sirva à vida do homem, seja um estábulo, um palheiro, um magazine, uma mercearia, uma loja de fazendas, uma estação de estrada de ferro, fábrica, múseu, etc.

No direito francês, onde foi usada a expressão maison (lei de 29-4-1845) e, posteriormente, bâtiments (lei de 11-7-1947), também se compreende nelas a isenção de tôda construção, não só destinada a habitação dos homens, como de animais, bem como para serviço e utilidade dos mesmos. (42)

SPòTA, analisando o dispositivo correspondente argentino diz que o vocábulo "casas" deve ser interpretado amplamente, sendo essa interpretação sobretudo racional, pois que o prejuízo que se causaria com a não isenção a um estabelecimento industrial não seria menor do que o que se causasse a ûma casa de habitação e suas dependências. (43)

(38) Delle servitù legali, n. ${ }^{\circ} 788$.

(39) Gianzana, Acque private, n. ${ }^{\circ} 1.635$.

(40) Op. cit., n. ${ }^{\circ} 1.636$.

(41) Com. del. Cod. Civ. Ital., vol. II, \& 1.217.

(42) Demolombe, Cours, vol. XI, n. ${ }^{\circ} 224$.

(43) Trat. de Der. de Águas, vol. II, n. ${ }^{\circ} 1.082-\mathrm{A}$. 
Quanto aos currais, pátios e jardins, devem achar-se vinculados aos edifícios, não devendo estar dêles separados por nenhum imóvel, público ou privado, (44) bastando entretanto que dependam das casas, sem necessidade de se encontrarem cercados.

Todavia, o nosso Código de Águas parece, como dissemos de início, explícito em sentido contrário à solução dada pelos civilistas em geral, exigindo ainda que os pátios, jardins, alamedas ou quintais sejam contíguos às casas de habitação.

Isto importa dizer que a simples proximidade não é suficiente para thes conferir a isenção.

Desde que haja de permeio outra propriedade entre a casa de habitação e o jardim ou o quintal, já não se verifica a hipótese da lei.

Assim, estão sujeitos ao aqueduto legal os jardins isolados.

Uma observação que se faz mister é a relativa à compreensão dos chamades "parques", entre os jardins.

Tal denominação é freqüente entre nós, para os jardins de dimensões mais acentụadas; mas também já vai tendo aplicação não só para os logradouros destinados à criação e ao colecionamento de animais selváticos, como também para terrenos destinados à conservação de certas espécies, quer vegetais, quer animais.

Para êsses casos, ainda que contenham habitações contíguas, não se deve aplicar a isenção legal, desde que aquêles prejuízos justificadores do benefício não apareçam concorrentemente. (45)

Resta examinar se os denominados "lugares sagrados", como sejam as igrejas, os cemitérios e os mausoléus, podem ser incluídos entre as casas de habitação.

Se dermos ao dispositivo da lei uma interpretação literal, estão todos excluídos do favor legal, a menos que se considere as primeiras como casas de habitação de Deus e os últimos como lugares de habitação de pessoas mortas.

Mas a imposição coativa do aqueduto, sendo uma disposição excepcional do princípio dominante da ilimitação da propriedade, deve ser tanto quanto possível preservativa dêsse princípio, de forma que a finalidade determinante da coação não ofenda outros ditames sociais tão respeitáveis quanto o da finalidade aludida.

Assim, o prudente arbítrio do julgador deverá saber pesar as circunstâncias quando se apresentarem essas hipóteses.

No mesmo caso se encontram os edifícios e construções monumentais, que se não destinem a habitação e tenham outras finalidades. (46)

(44) Idem, n. ${ }^{\circ}$ 1.082-B.

(45) Gianzana, op, cit., n. ${ }^{\circ} 1.636$.

(46) Mazza, Dei Diritti sulle acque, n. 53. 


\section{RESTRIÇÃO ÀS ISENÇÕES}

O Código exclui da isenção mesmo as casas de habitação e suas dependências, nêle previstas, no caso de concessão por utilidade pública, quando ficar demonstrada a impossibilidade material ou econômica da execução das obras sem a utilização dos prédios favorecidos pela restrição. (47)

A utilidade pública é motivo previsto, constitucionalmente, para a restrição do direito de propriedade; e até para a sua completa expropriação. (48)

Dela cogitou o Código Civil, exemplificando alguns casos em que a sua verificação ocorria, isto ao lado dos casos de necessidade pública, que eram, outrossim, considerados no diploma constitucional brasileiro vigente ao tempo da promulgação do referido Código. (49)

Lei posterior regulou o assunto mais amplamente e deu considerável acréscimo a essa exemplificação, nela figurando hipóteses que se enquadram diretamente na matéria estudada, em relação aos aquedutos. (50)

Desde que se não trate de interêsse público, e tão exclusivamente para servir a interêsse privado, desaparece a restrição e subsistem as isenções, ainda que haja impossibilidade material ou econômica para a execução do aqueduto, sem a utilização dos prédios favorecidos pela lei.

A impossibilidade material, necessária à restrição, no caso de concessão por utilidade pública, decorre quase sempre de acidentes geográficos: uma parede maciça de montanha; um rio; o mar; um precipício, etc.

A impossibilidade econômica tem como causa, em regra, dificuldades de ordem topográfica que, muito embora transponíveis, acarretariam à execução uma soma de dinheiro de tal monta, a tornar o benefício irrisório ou de nula compensação diante dos gastos.

\section{SUMMARY}

1. The legal acquedutus servitude has to be established (1)either by decree of the Government, in case of conession based on public utility (2) or by a judicial authority, in any other cases. norms.

2. Government decretation of the servitude analysed. Exceptions to the general

3. Judicial decretation of the servitude discussed. Provisions of the Civil Code on the matter. Historical analysis of the institution and of the legal remedies against violations of rights of owner or possessor of the waters.

4. Decretation of the servitude in the case of deeds of partitions. Provisions of the Code of Procedure on the matter.

(47) Cod. de Águas, art. 118, parágrafo único.

(48) Const. Federal, art. 141, \& 16.

(49) Cod. Civil, art. 590 e Const. Federal de 1891, art. 72 , § 17.

(50) Decreto-lei n. 3.365 , de 21-6-1941, art. 5. 
5. Persons entitled to ask for the servituda, according to the Civil Code, viz., owner, usufructuarium, usuary, renter, resident, concessionary, etc.

6. The direction, nature and form of the aqueduct should cause the minimum possible damage to the servient property. Provisions of both the Civil Code and the Code of Waters.

7. Decretation of the servitude and the indemnity due to the servient property. Provisions of the Code of Waters. Restrictions concerning the suits of those who claim to have rights upon the servient property.

8. The amount of the indemnity to be established by the judicial authority upon having obtained the opinion of experts appointed, by both litigants.

9. Limits of the indemnity as established by the Civil Code. The hypothesis is not of expropriation but of restriction upon the use of property.

10. A money deposit may be required by the owner or possessor of the servient property from the dominant property. Provisions of the Civil Code on the matter. The opinion of several jurists quoted. Provisions of the Code of Procedure.

11. Exemptions to the servitude as established, in principle by the Code of Waters. Reference to provisions of the Portuguese legislation and to the Italian Civil Code. Provisions of the Brazilian Civil Code.

12. Exemptions to the servitude in foreign legal systems, particularly the Italian and the Portuguese Civil Codes.

A administração é a parte predominante do govêrno; é o govêrno em ação; é o executivo atuante, o aspecto mais proeminente do govêrno... O campo da administração é um campo de negócios no sentido clássico da palavra. Está afastado da balbúrdia e das lutas políticas e, em muitos aspectos, da controvertida arena do direito constitucioral. Está para a vida política assim como a maquinaria para o produto manufaturado. Ao mesmo tempo, porém, situa-se muito acima do nível enfadonho da simples minúcia técnica, por isso que está diretamente ligado, pelos elos de seus princípios fundamentais, às máximas duradouras e às verdades permanentes da sabedoria e do progresso político...

Woodrow Wilson, O Estudo da Administração, Cadernos de Administração Pública, E.B.A.P., 1955. 